Keio J. Med. 33: 59-82, 1984

\title{
ISLAND FASCIOCUTANEOUS FLAPS OF DORSAL TRUNK AND THEIR APPLICATION TO MYOCUTANEOUS FLAP
}

\author{
HIDEO NAKAJIMA and TOYOMI FUJINO \\ Department of Plastic and Reconstructive Surgery, \\ Keio University Hospital, Tokyo, Japan
}

(Received for publication January 11, 1984)

The blood supply to the skin is the principle factor which determines the extent of survival of skin flaps and myocutaneous flaps.

Daniel ${ }^{1}$ (1973) classified the vascular supply to the skin into two systems of vessels. They are direct cutaneous vessels and musclocutaneous ressels. The former is the system of the vascular supply in non-muscular parts like the axilla or the groin region and the latter is the vascular supply system in the fixed skin area, for example the dorsal trunk and limbs. Daniel reported that as for fixed skin animals such as pigs, apes, men and so on, the muscutaneous vessels were the primary ressel but they were supplemented by limited non-essential direct cutaneous vessels.

As the panniculus is vestigial in man, it has been said that there is not any extensive and strong vascular network organized by the cutaneous vessels on the fascia. Is it true? We know that the skin region of myocutaneous flap including the fascia is enlarged even if it contains only the fascia. And we also notice that the enlarged region varies in the region of the body. It was supposed that it would be dependent on the difference between vascular networks on the fascia (Nakajima,-2 1981). Ponten ${ }^{3}$ (1981) reported the fasciocutaneous flap in the leg, and Haertsch ${ }^{4,5}$ (1981) anatomically proved the fascial plexus which was the foundation of the vascular supply of the fasciocutaneous flap.

This paper presents that even the skin of the dorsal trunk regarded as the most fixed skin area can be adequately nourished by the direct cutaneous artery and the cutaneous branch of segmental muscular artery through the fascial plexus, even if musculocutaneous arteries are severed. We carried out an animal experiment, but we would like to report only clinical cases this time. 


\section{Island fasciocutaneous flaps}

1. Cervicodorsal flap

The blood supply to the skin on the trapezius muscle is due to the cutaneous branch of superficial cervical vessels and the posterior intercostal perforators, except for musculocutaneous perforators from underlaying muscule. The former perpendicularly perforates the trapezius muscle and its fascia as the cutaneous branch and the latter perforates the fascia as the direct cutneous vessels. And then they form the vascular network on the fascia (Fig. 1). After microangiography of the skin above the trapezius is done (Fig. 2), the skin is spilt into three layers, which are the dermis and the upper half of subcutaneous layer, the lower half of it, and fascial layer (Fig. 3). The superficial cervical artery and the posterior intercostal perforator can be seen to form the tight network in the lower two layers (Fig. 4). The superficial cervical artery perforates the trapezius muscle from the outside of the verterbra prominence and from several centimeters distance of the anterior border of the muscle (Fig. 5).

Case 1 (Fig. 6): A case of the angioma of a right half of a face that had been reconstructed by the pectoralis major myocutaneous flap after evulsion of the tumor, but the patient had been hardly able to open his mouth for lack of the oral lining. After ablation of the scar and coronoidectomy we formed $7 \times 30 \mathrm{~cm}$ sized skin flap containing the fascia in the paramedian back, whose pedicle was the superficial cervical artery. A part of it was denuded and passed under the skin of the neck. Thus we made up for the lack of the oral lining and the cheek skin.

Case 2 (Fig. 7): The defect of $8 \times 8 \mathrm{~cm}$ sized skin after ablation of the tumor of occipital region. It was covered with $7 \times 30 \mathrm{~cm}$ sized cervicodorsal flap rotated in a 180-degree arc. The island cervicodorsal flap could cover the whole region of the head and the neck (Fig. 8).

\section{Infrascapular flap}

The back from the scapula to the iliac crest is chiefly covered with the latissimus dorsi muscle and the vascular supply to the skin above it relies on the circumflex scapular artery, the thoracodorsal artery, V to XII intercostal perforator and the lumbar perforator. Compared with the size of the latissimus dorsi muscle, the cutaneous vascular territory of the thoracodorsal artery is quite narrow (Nakajima, ${ }^{2} 1981$ ). Even in this territory, the large fasciocutaneous flap, having several direct cutaneous vessels as the nutrient artery, can be made. Nassif ${ }^{6}$ described that even the skin on the latissimus dorsi muscle called the parascapular flap was nourished by the circumflex scapular artery. In the medialinferior portion of the back from the scapula, the new fasciocutaneous can be 
raised as the infrascapular flap, whose pedicle is the sixth dorsolateral branch of posterior intercostal perforator. We can show more extended infrascapular flap combined with the parascapular flap (Fig. 9). It is the gigantic island flap supported only by the circumflex scapula artery and the sixth posterior intercostal perforator (which emerges in the triangle of auscultation and is the biggest) as pedicles (Fig. 10).

Case (Fig. 11): Local recurrence of mamma carcinoma and radiation ulcer of axilla and anterior chest. It was reconstructed by $15 \times 18 \mathrm{~cm}$ sized combined infrascapular flap islanded perfectly.

3. Lumbo-gluteal flap

If the skin above the gluteus maximus muscle is raised as the fasciocutaneous flap, it is also nourished by some arteries except the musculocutaneous perforator of the superior and inferior gluteal arteries. As the third or fourth lumbar perforator is a strong direct cutaneous artery, this can be used as its pedicule of the fasciocutaneous flap spreading as far as the trochanta or the groin region. We name it lumbo-gluteal flap (Fig. 12).

Case (Fig. 13): Sacral decubitis. The patient of this case could walk, so it was repaired by $8 \times 25 \mathrm{~cm}$ sized lumbo-gluteal flap, instead of gluteus maximus myocutaneous flap.

\section{Fasciocutaneous flap's application to the extended myocutaneous flap}

We suggest that the extent of the fasciocutaneous flap which can be attached to the myocutaneous flap chiefly depends on the structure of the epifascial plexus of it. Basically, the network is strong in the territory of the direct cutaneous vessel and the cutaneous branch of muscular vessel. It is weak in that of musculocutaneous perforator.

1. Anteriorly extended latissimus dorsi myocutaneous flap

The dominant nutrient arteries on the lateral abdominal wall are the lateral intercostal perforators. They form the vascular network on the fascia of external abdominal oblique muscle and anastomose with the lateral branch thoracodorsal artery (Fig. 14). The thoracoepigastric ap depends on this network.

Case (Fig. 15). Radiation ulcer of anterior chest. The ablated range was the size of $22 \times 24 \mathrm{~cm}$ beyond the part of the sternum. The extended myocutaneous flap which was obtained by attaching $15 \times 20 \mathrm{~cm}$ sized fasciocutaneous flap to $7 \mathrm{~cm}$ latissimus dorsi myocutaneous flap in width was used for the reconstruction. 
2. Posteriorly extended latissimus dorsi myocutaneous flap

As previously stated, the skin on the trapezius muscle and the scapula have the strong networks on the fascia. These networks inoculate with the medial branch of thoracodorsal artery (Fig. 16).

Case (Fig. 17): Radiation ulcer of neck. The defective skin after ablation of the scar was in the range of $8 \times 22 \mathrm{~cm}$. The extended myocutaneous flap which was obtained by attaching $8 \times 14 \mathrm{~cm}$ sized fasciocutaneous flap to $6 \mathrm{~cm}$ latissimus dorsi myocutaneous flap in width was used for the reconstruction.

3. Gluteal-thigh-groin bilobed myocutaneous flap

The blood supply in the groin region depends on the direct cutaneous vessel of superficial circumflex iliac vessel, accordingly the fascial plexus well. The gluteus maximum myocutaneous flap can safely extend to the groin region.

Case (Fig. 18): Carcinoma of anus. The rectum and the anus with the gluteal muscle were extirpated en bloc. As the large gluteal-thigh flap 7 was needed, the biolobed myocutaneous flap was devised in the way of adding the ala to the groin region for the reconstruction.

\section{DISCUSSION}

From the result mentioned above, it has become clear that all regions of the skin of the dorsal trunk can be nourished only by several direct cutaneous vessels and cutaneous branches of segmental muscular vessels (Fig. 19). What on earth does the fact mean? As for fixed skin animals such as men and pigs, there may be another vascular network in the subcutaneous layer below the subdermal plexus in the whole body, even if the panniculus carnosus degenerates or ceases to exist. The network may get the vascular supply not only from musculocutaneous vessels and direct cutaneous vessels but also from the cutaneous branches which emerge through the muscle or intermuscular space and septocutaneous perforators.

The fasciocutaneous flaps presented in this paper are island flaps, so we may categorize them into axial pattern flaps. Infrascapular flap and lumbogluteal flap are supplied by direct cutaneous vessels as in the case of groin flap, but cervicodorsal flap is obviously different from them in the vascular pattern. It is the new type of axial pattern flap in the origin of blood supply.

It is time to review the concept of axial pattern and random pattern or that of direct cutaneous and musculocutaneous which has been used for the last decade.

\section{SUMMARY}

Several new island fasciocutaneous flaps have been reported. They depend 
on new concept of the vascular supply to the skin. This concept different from one used up to the present will be applied hereafter.

\section{REFERENCES}

1. Daniel, R. K. and Williams, H. B.: The free transfer of skin flaps by microvascular anatomosis. Plast. \& Reconstr. Surg. 52: 16-31, 1973

2. Nakajima, H., Maruyama, Y. and Koda, E.: The definition of vascular skin territories with prostaglandin $\mathrm{E}_{1}$ - the anterior chest, abdomen and thigh-inguinal region. Brit. J. Surg. 34: 258-263, 1981

3. Ponten, B.: The fastiocutaneous flaps; its use in soft tissue defect of the lower leg. Brit. J. Surg. 34: 215-220, 1981

4. Haertsch, P.: The surgical plane in the leg. Brit. J. Surg. 34: 464-469, 1981

5. Haertsch, P.: The blood supply to the skin of the leg: a post-morte investigation. Brit. J. Surg. 34: 470-477, 1981

6. Nassif, T.M. and et al.: The parascapular flap: a new cutaneous microsurgical free flap. Plast. \& Reconstr. Surg. 69: 591-600, 1982

7. Hurwitz, D., Swartz, W. M. and Mathes, S.J.: The gluteal thigh flap: a reliable, sensate flap for the closure of buttock and perineal wounds. Plas. \& Reconstr. Surg. 68: 521-532, 1981 

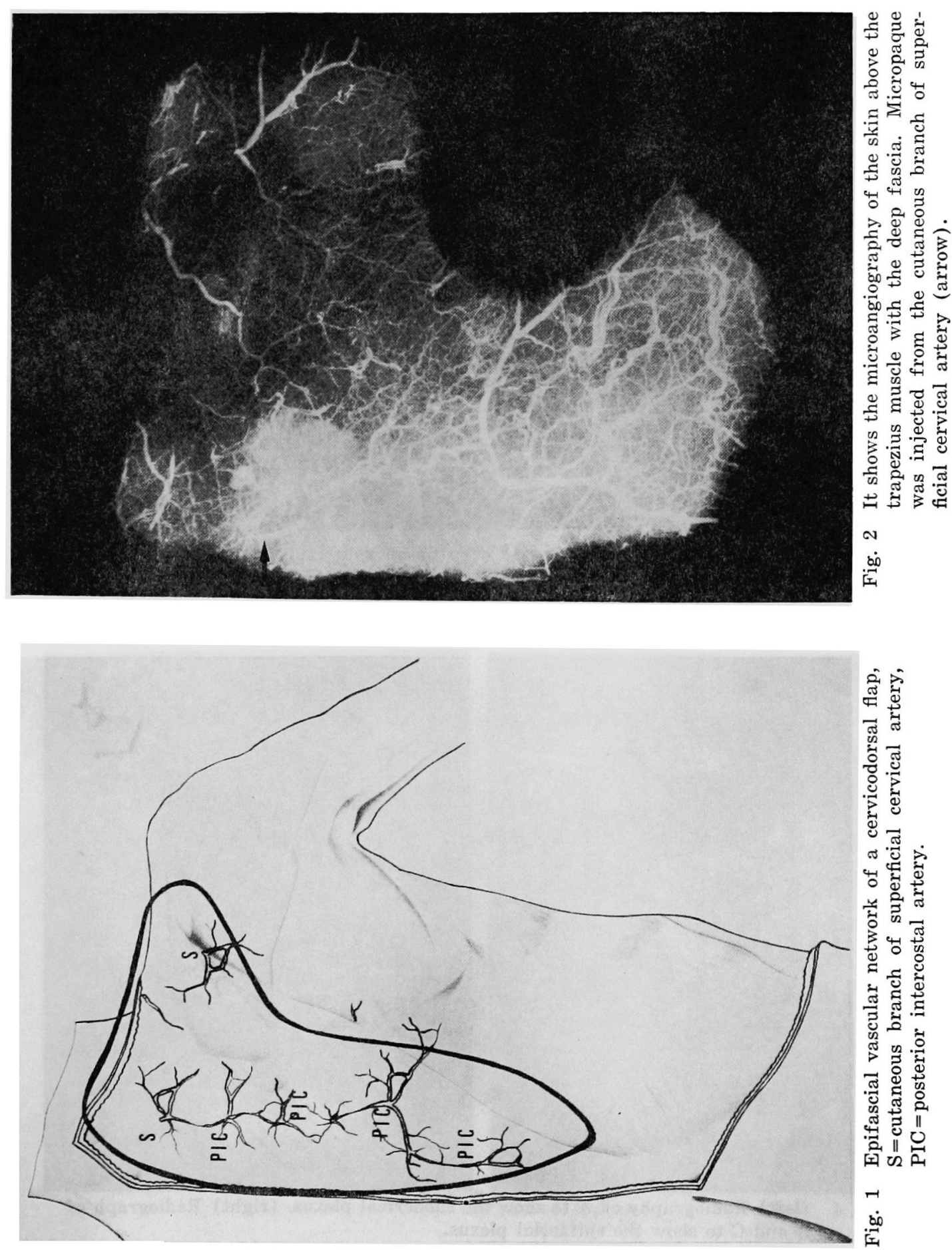


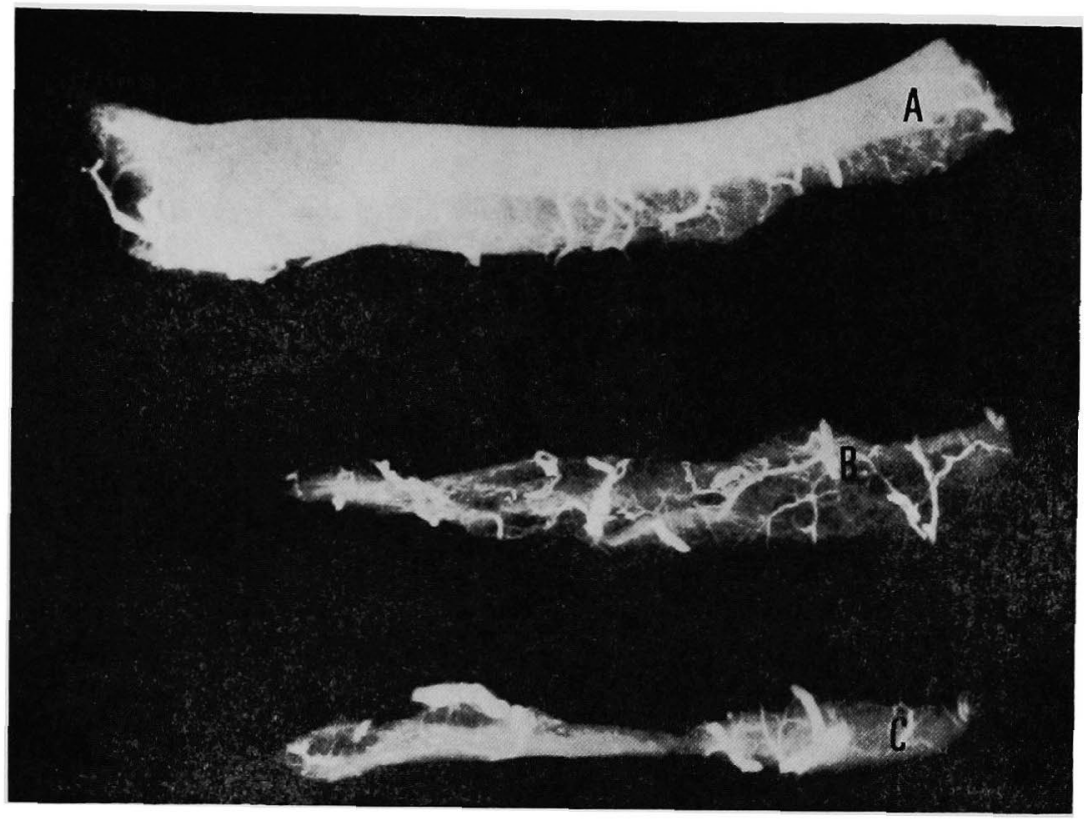

Fig. 3 The s'in involving the deep fascia split into three layers. A: the dermis and the upper half of subcutaneous layer. $\mathrm{B}$ : the lower half of it.

C: the fascial layer.

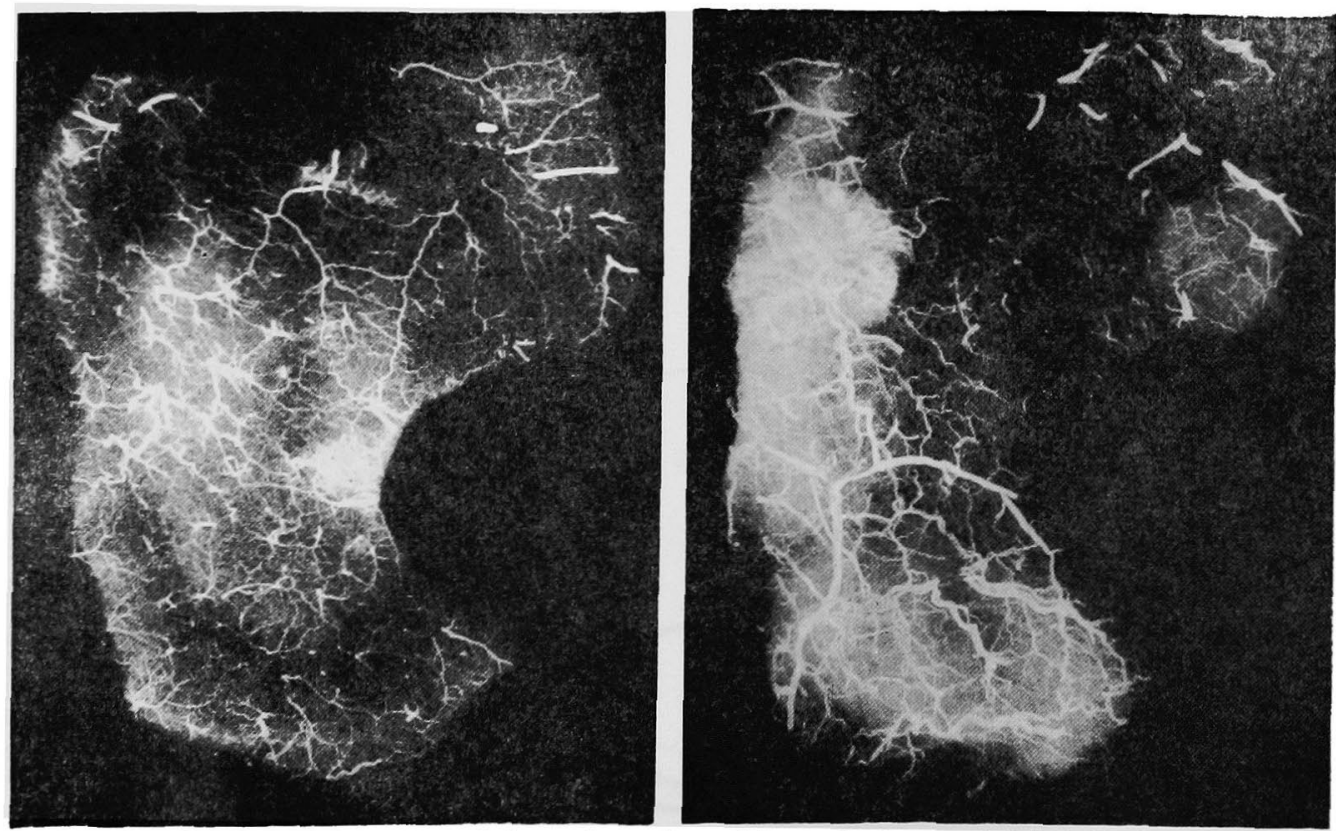

Fig. 4 (left) Radiography of A to show the subdermal plexus. (right) Radiograph of $\mathrm{B}$ and $\mathrm{C}$ to show the epifascial plexus. 


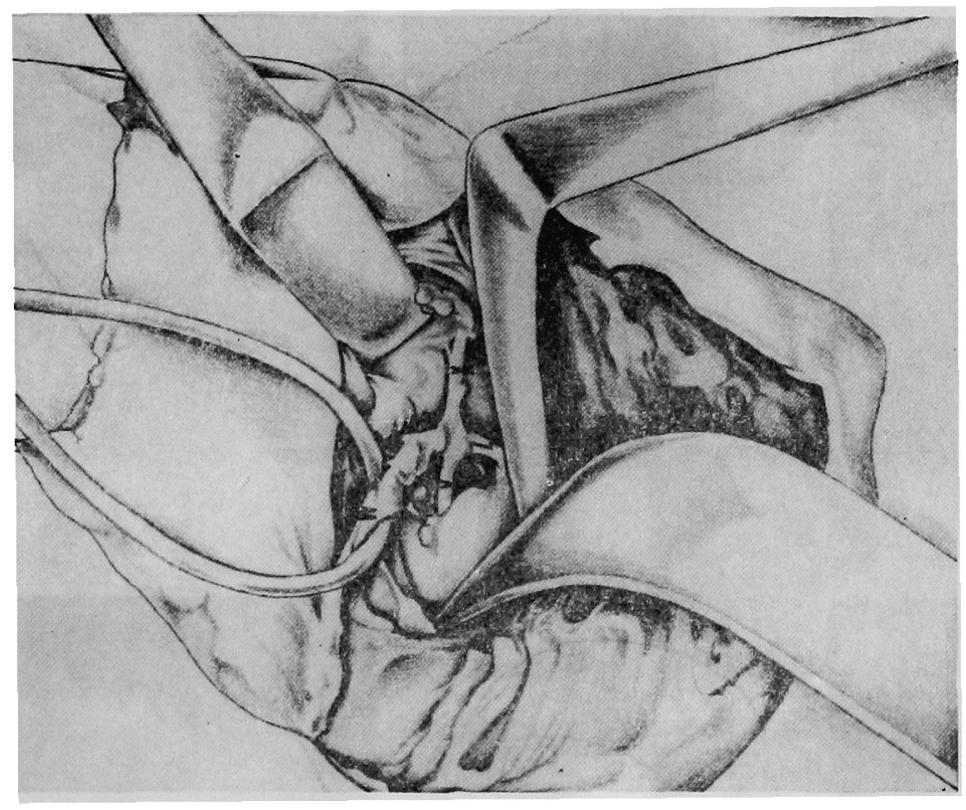

步

웅

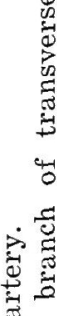

Lo

造造

哥

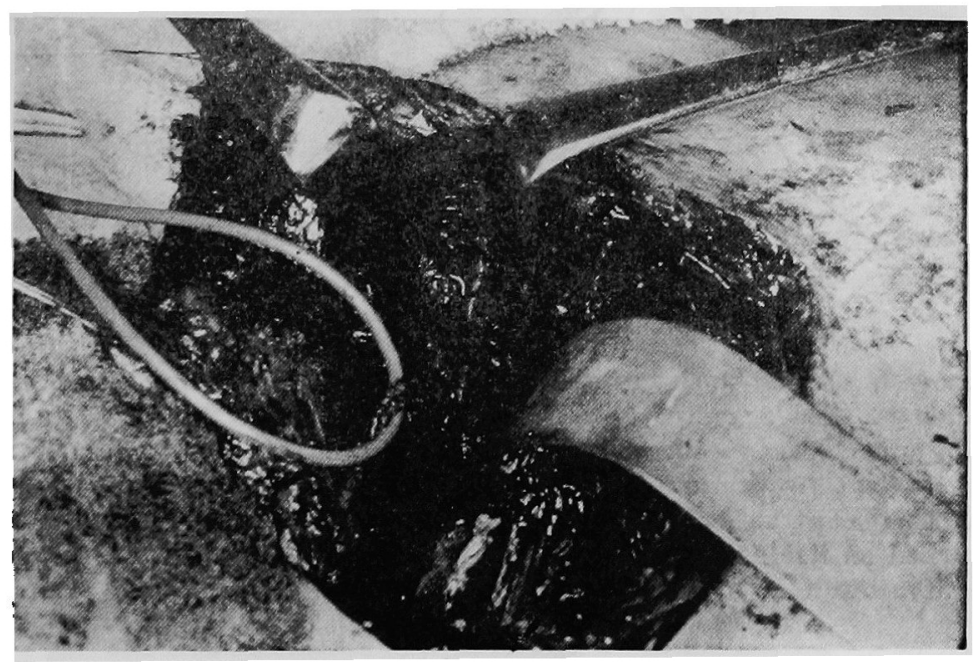

है:

尔

पै

तु है क्ष

苟.

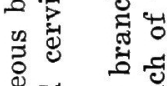

政

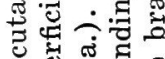

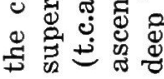

$\ddot{B} \ddot{x} \ddot{\sim} \ddot{N}$ 

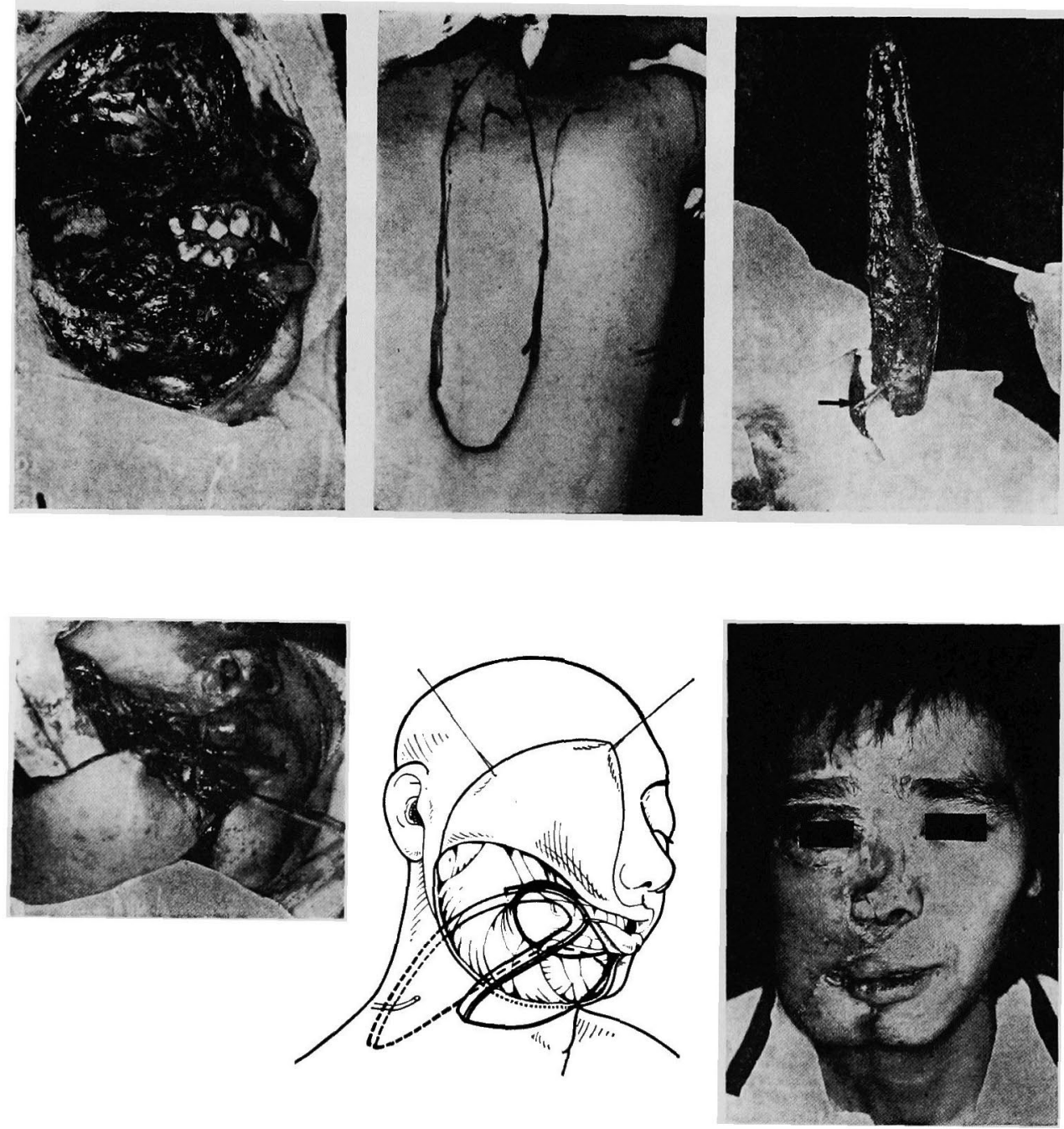

Fig. 6 Case 1 (above left) Full-thickness defect after releasing scar contracture and coronoidectomy. (above center) A $7 \times 30 \mathrm{~cm}$ cervicodorsal flap planned in paramedian dorsal area. (above right) The flap raised completely islanded by superficial cervical artery (arrow). (below left, center) The proximal portion of it provides the intraoral limung. Central cutaneous fold deepithelized and the flap turned on itself to allow the distal half to provide external coverage. (below right) Result at 6 months. 

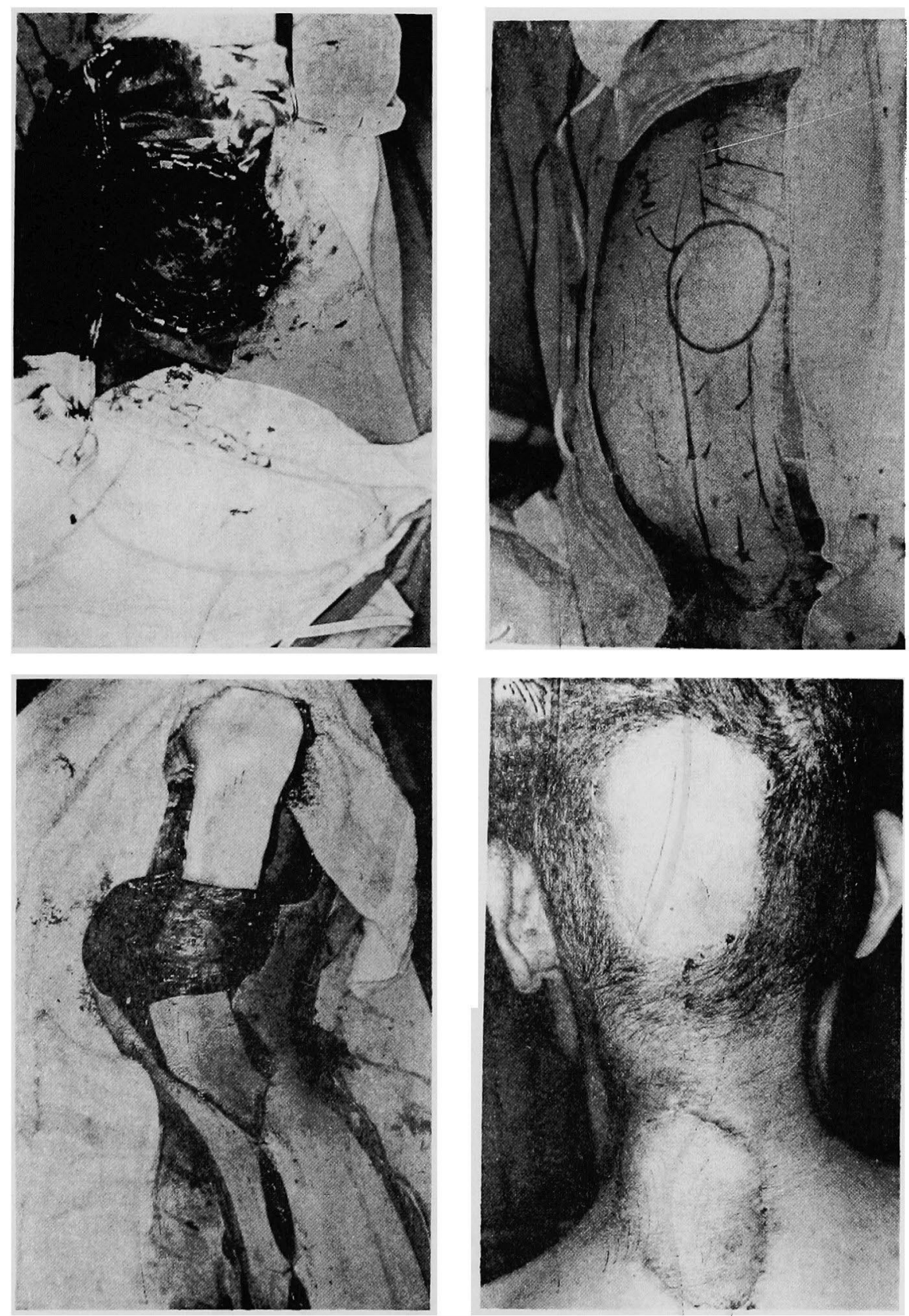

Fig. 7 Case 2 (above left) Surgical defect $8 \mathrm{~cm}$ in diameter, exposing bare occipital bone, after extirpation of scalp tumor. (above right) Diagrammed cervicodorsal flap $7 \times 30 \mathrm{~cm}$ size. (below left) The flap elevated and rotated to cover the defect. (below right) Postoperative view. 


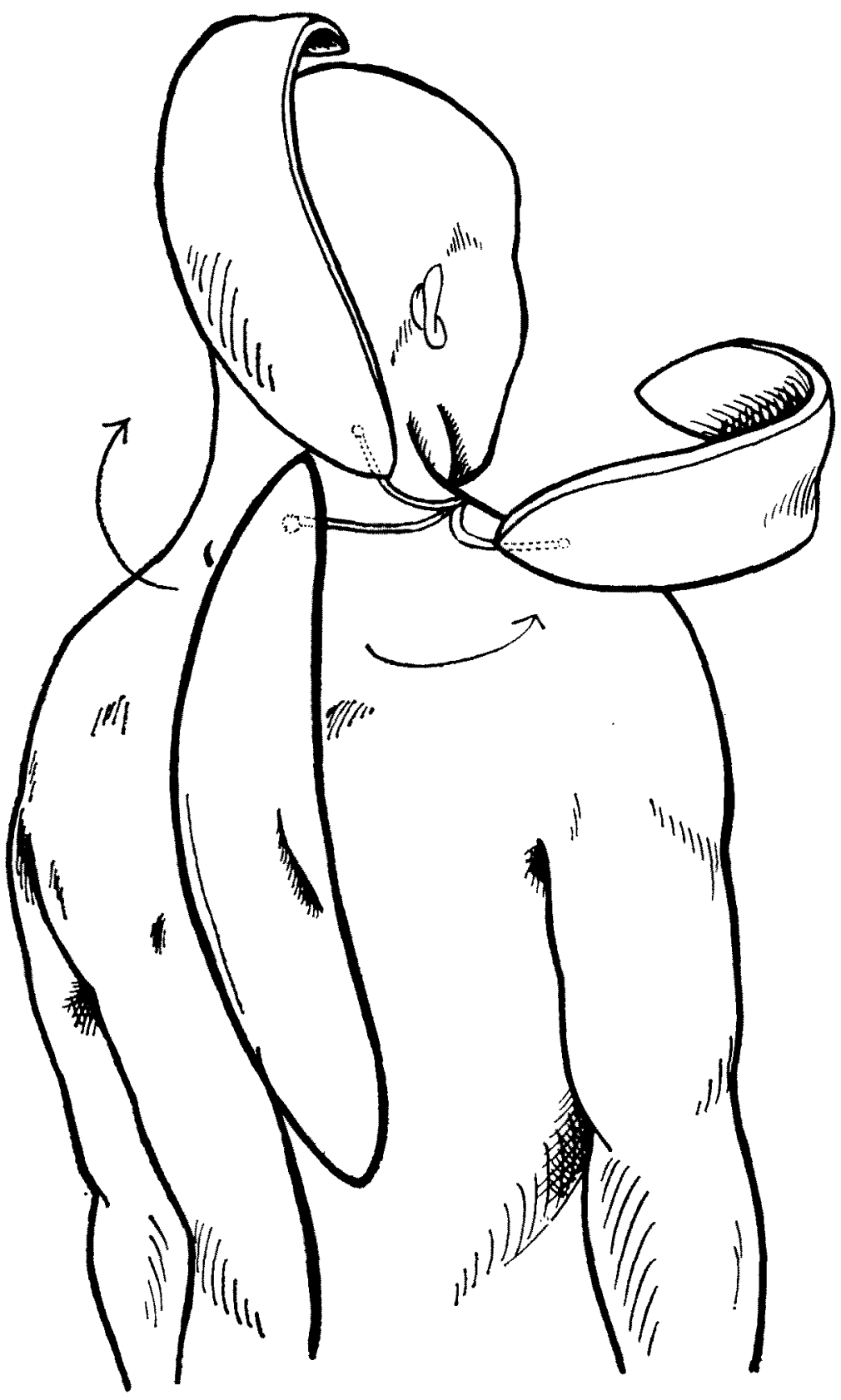

Fig. 8 Rotation arc of island cervicodorsal flap. 

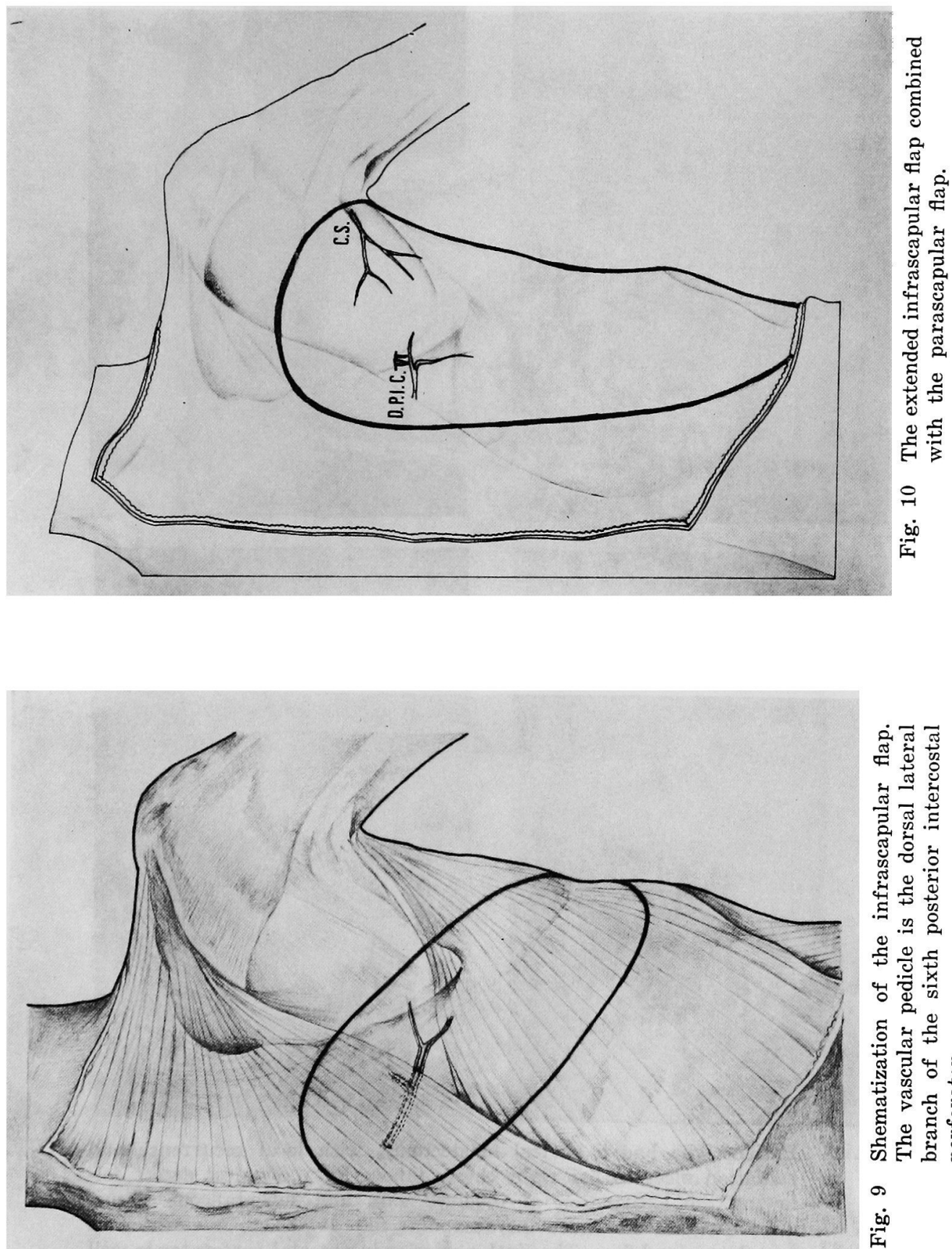

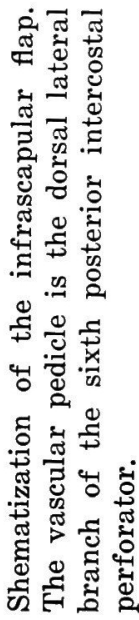

o

章 

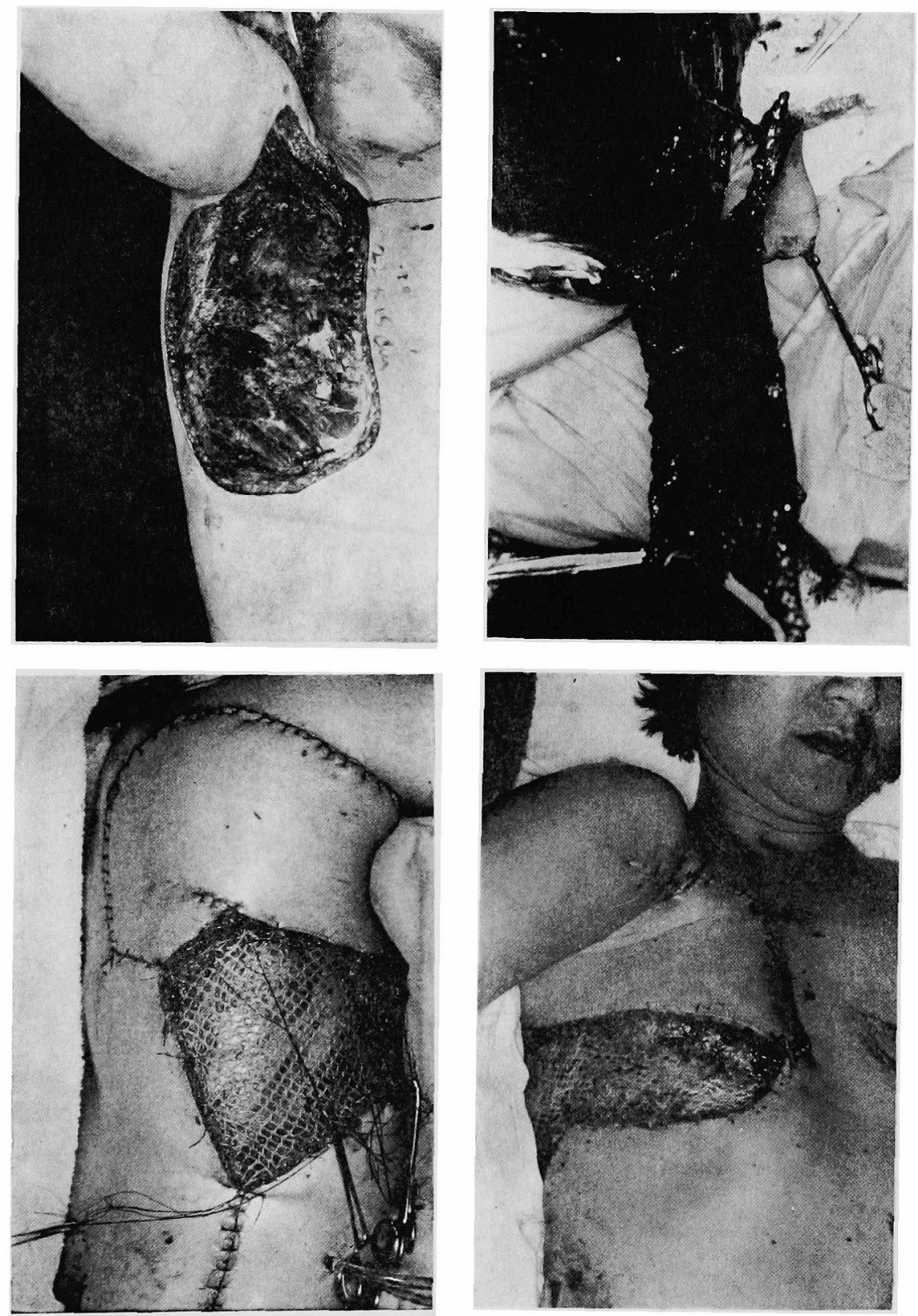

Fig. 11 Patient who had a radical mastectomy, with local recurrence and radiation ulcer in her right chest. (above left) Surgical defect following the extirpation of involved skin and subentaneous tissue. (above right) Extended infrascapular flap $15 \times 38 \mathrm{~cm}$ is elevated as complete island flap. The sixth posterior intercostal perforator is well seen (arrow). (below left) The immediate post-operative appearance. (below right) Result at 3 weeks. 


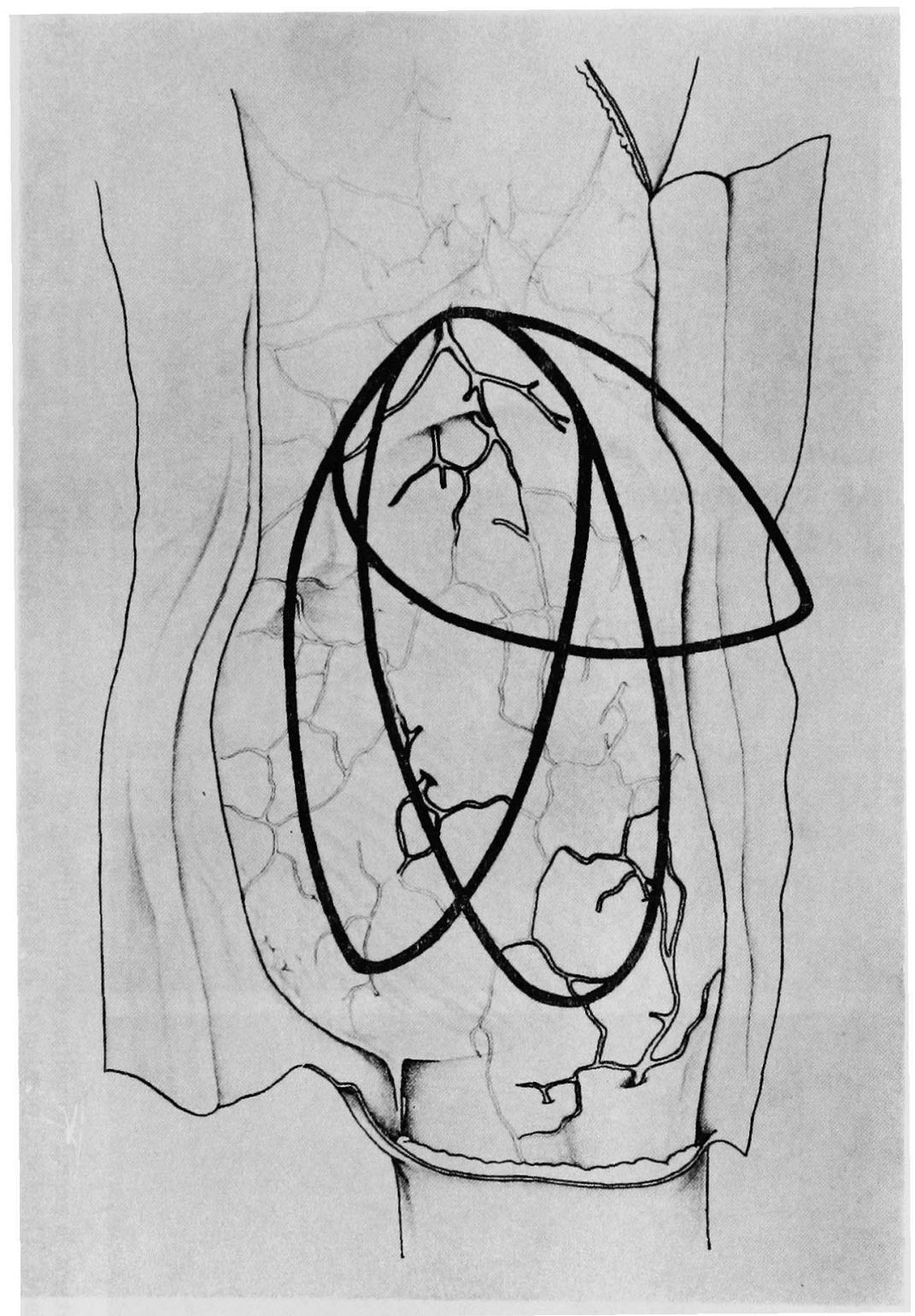

Fig. 12 The lumbogluteal flap.

The pedicle is the dorsal branch of the third or fourth lumbar artery and vein. 


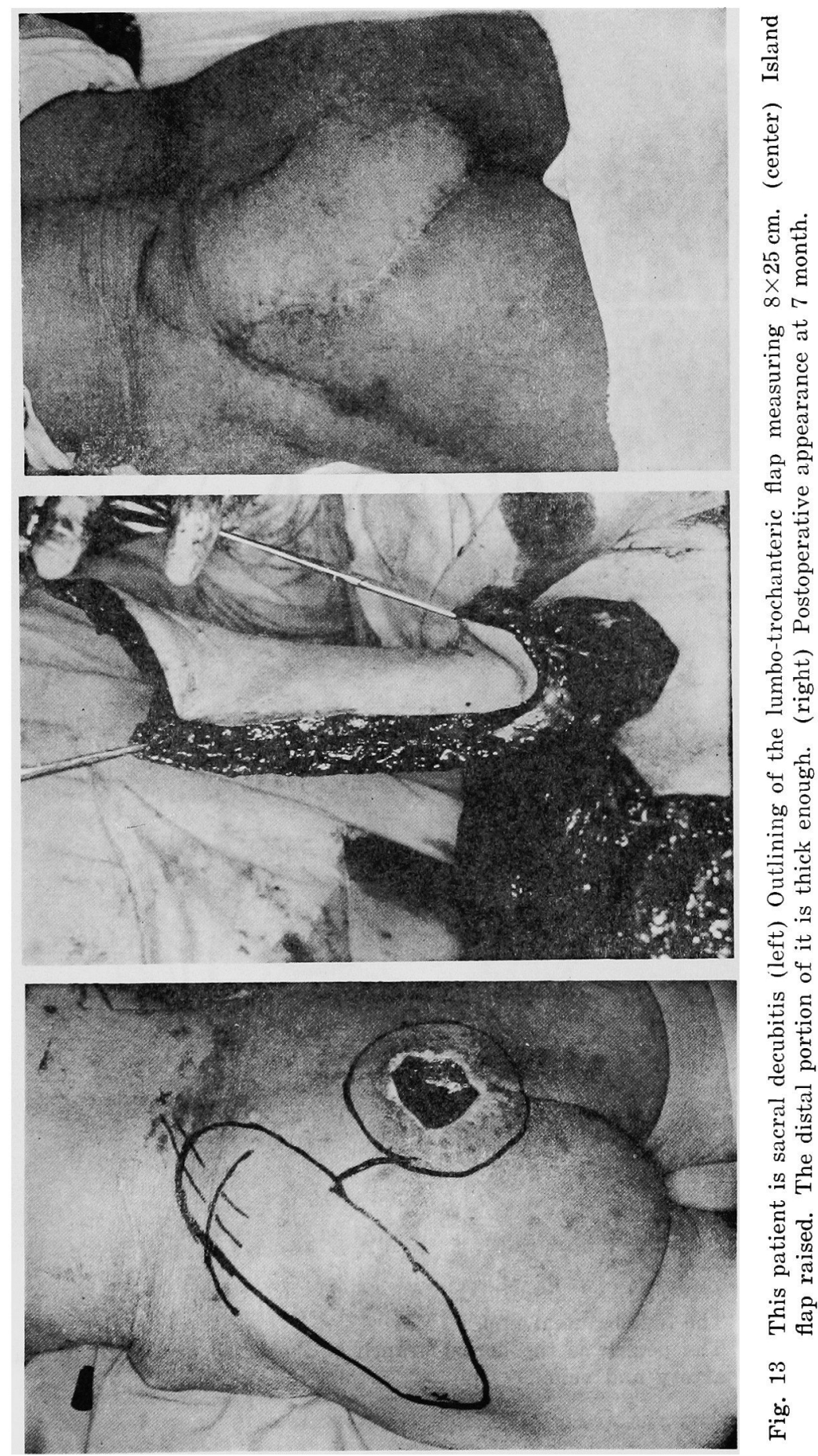




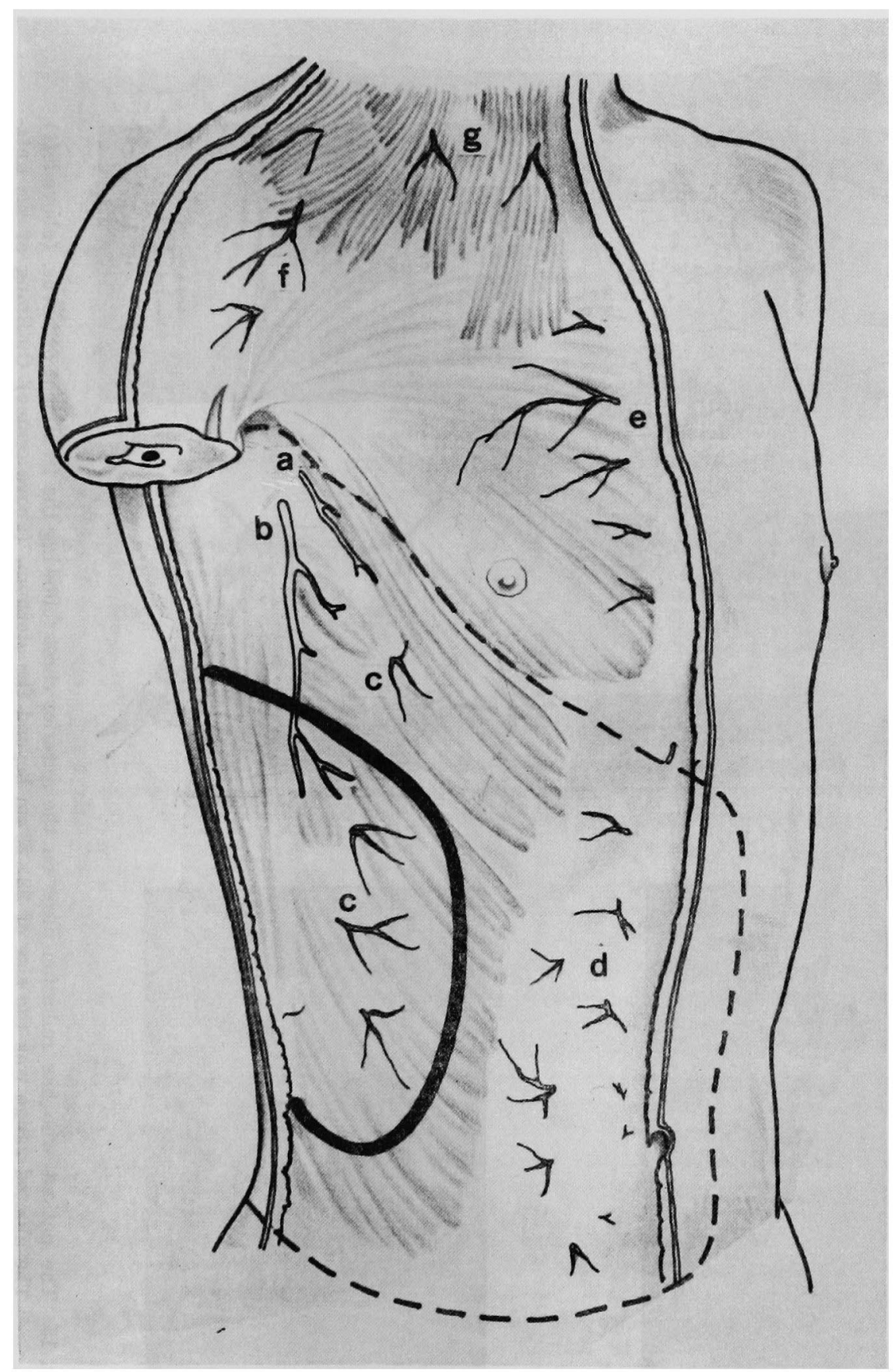

Fig. 14 Epifascial vascular network of the lateral chest is formed with the lateral thoracic vessels (a), the cutaneous branch of thoracodorsal artery, thoracoepigastric vein (b) and lateral intercostal perforators (c). 

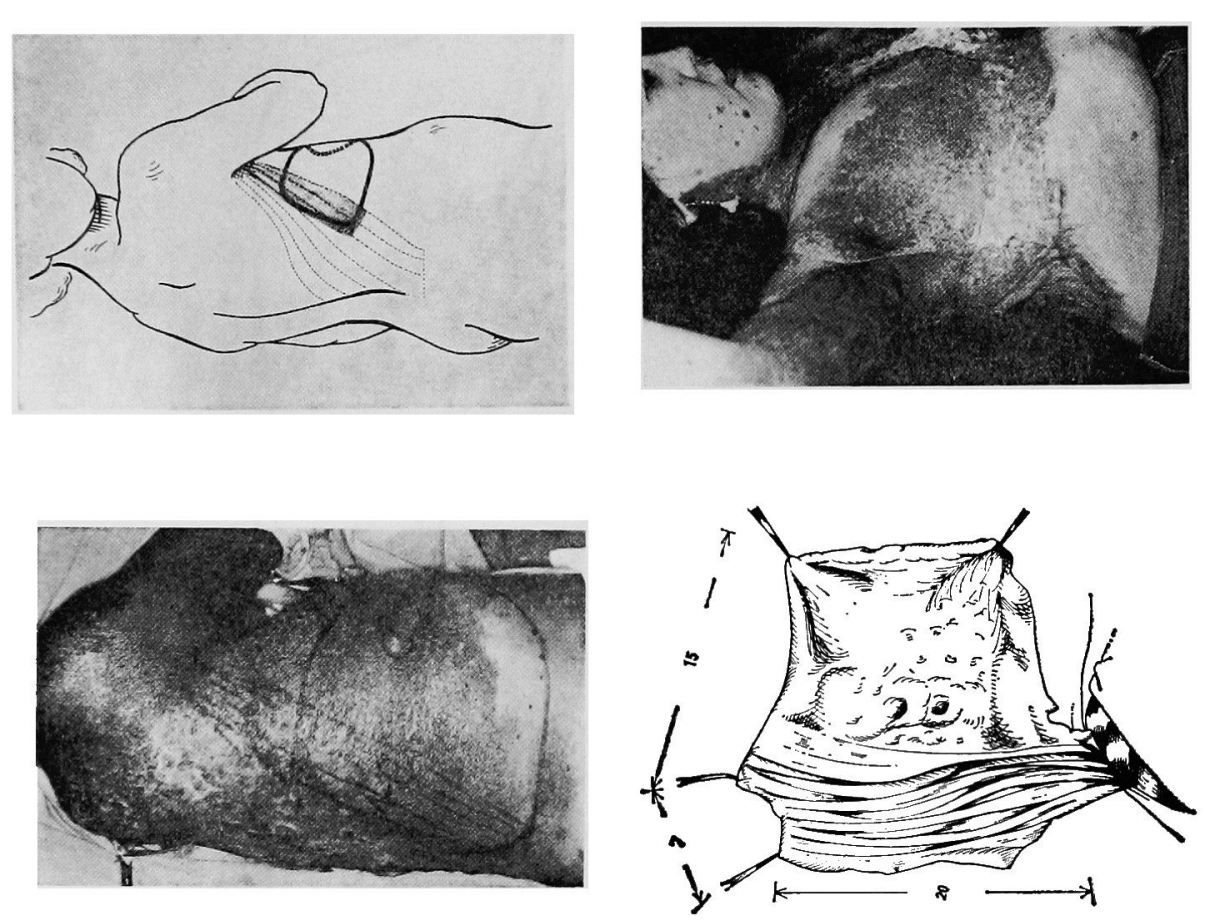

志戬

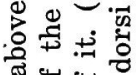

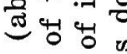

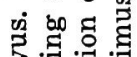
记 फ造密

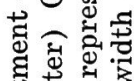

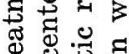

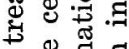
害客密 60 饮

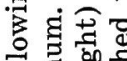
귱 豈.

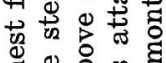

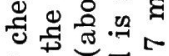
兽总

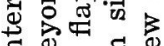
ส ¿ 덩 웡요 ติ ริ $\times$ 겅

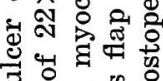

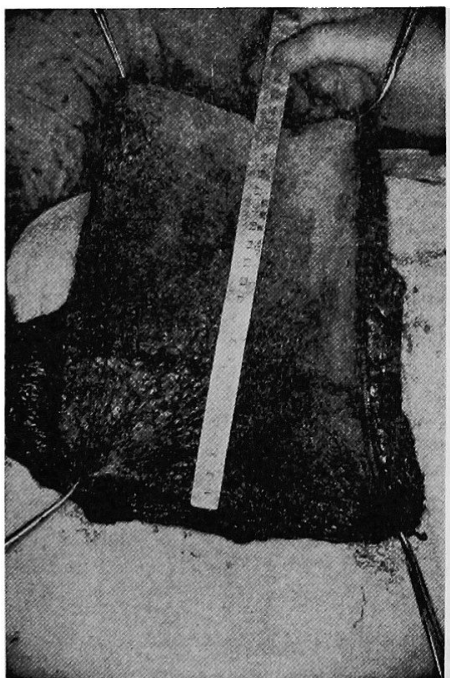
ब च 总. 䨔 प

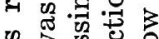

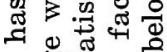
承焉运 넘웡

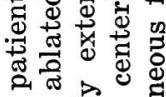

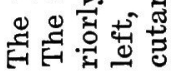
10 空 


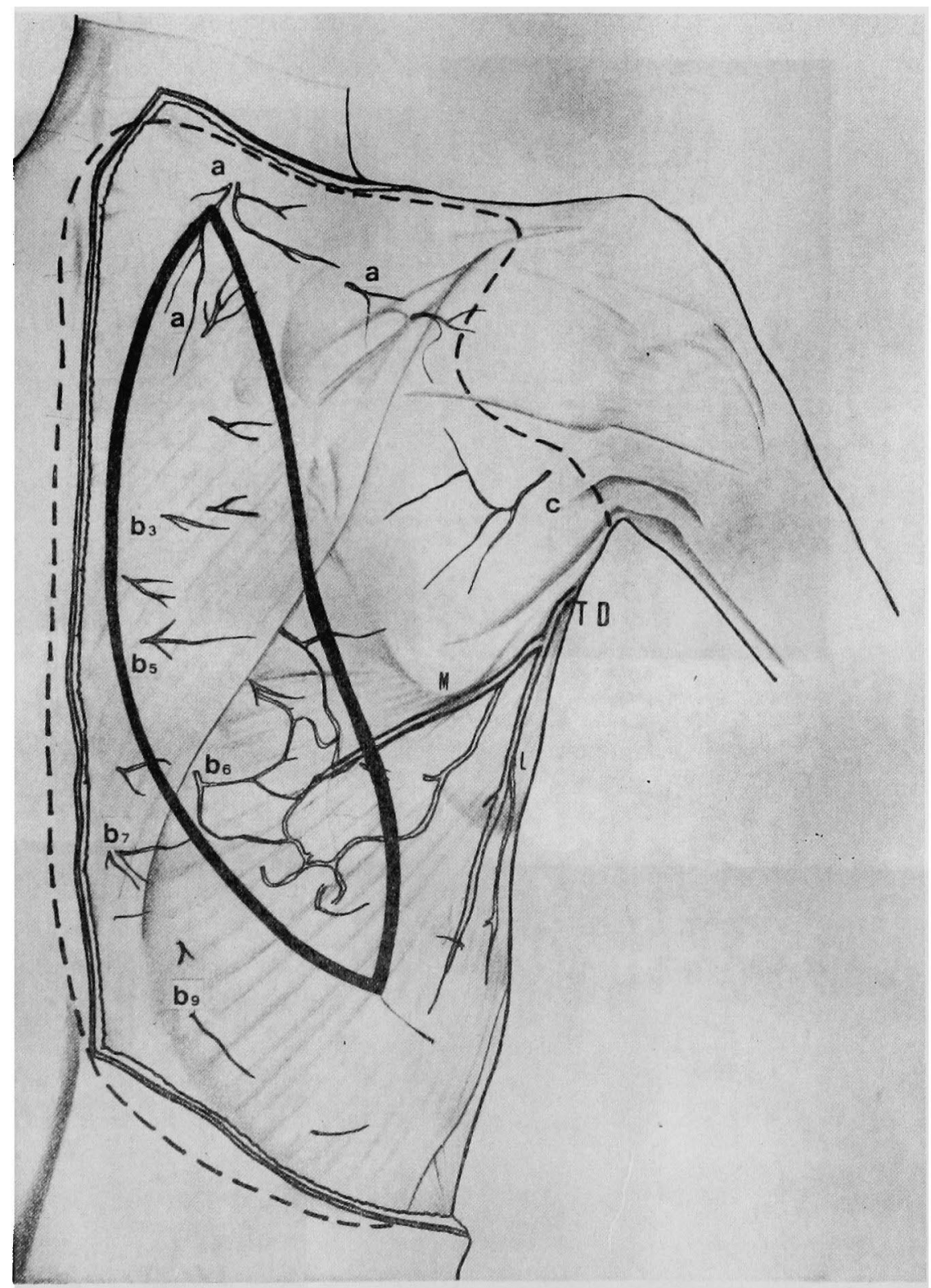

Fig. 16 The vascular architecture of posteriorly extended latissimus dorsi myocutaneous flap. The medical branch of thoracodorsal artery anastomoses to the fascial plexus of the back. 

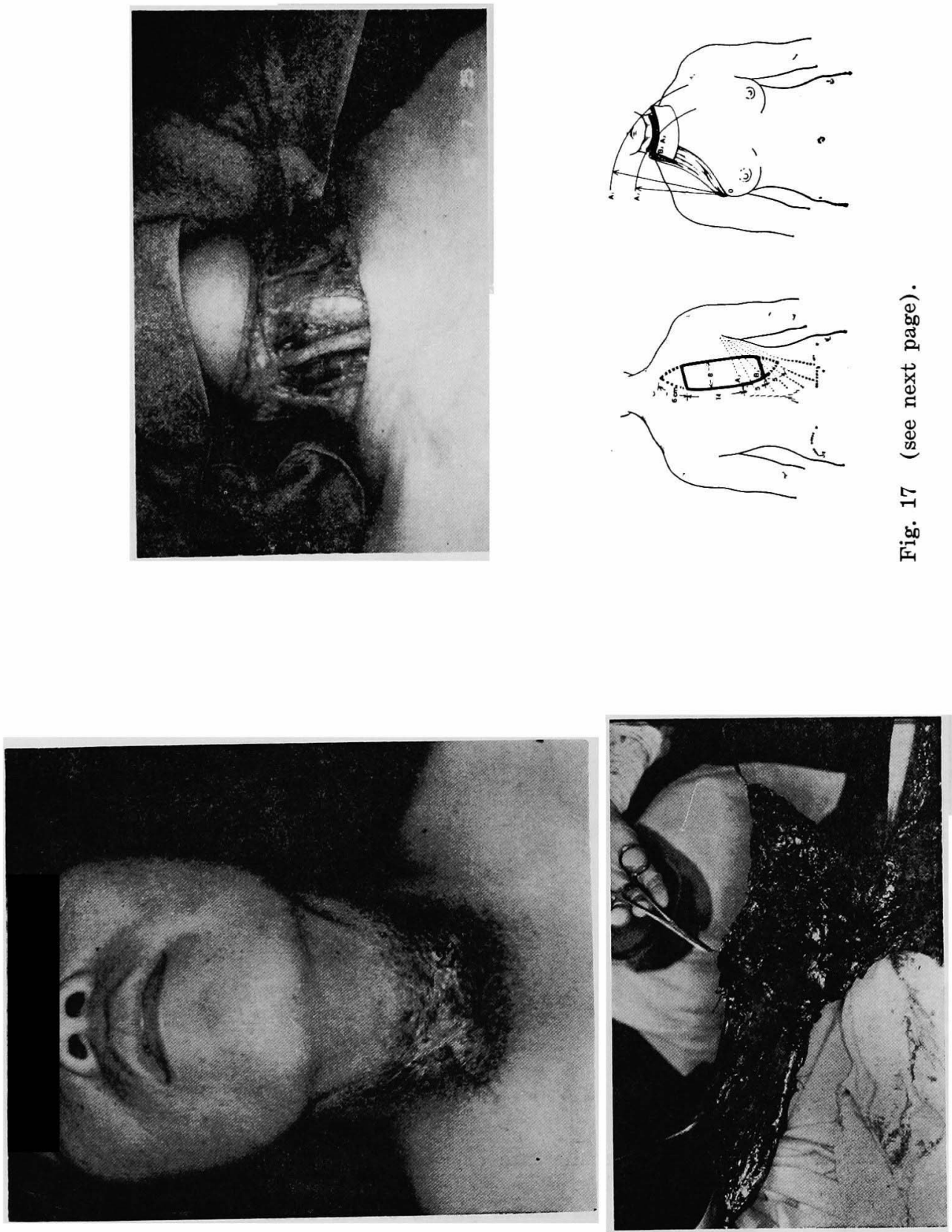


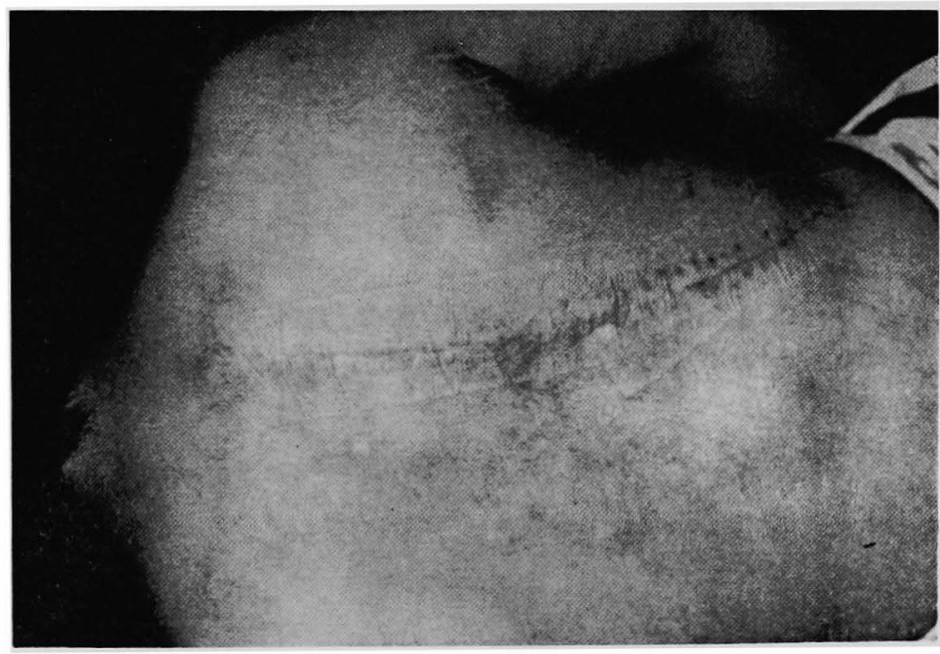

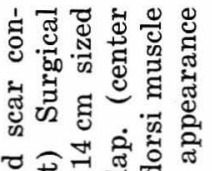

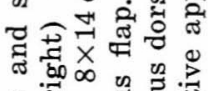
क

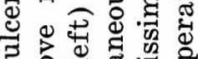

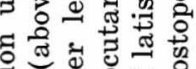
“ 丞 छ

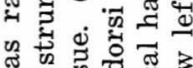
द्व 0.00

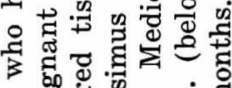

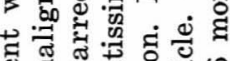

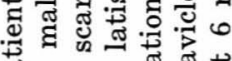

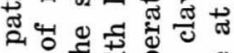

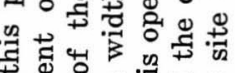
ॠ

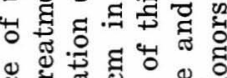

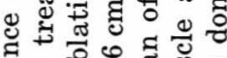
节

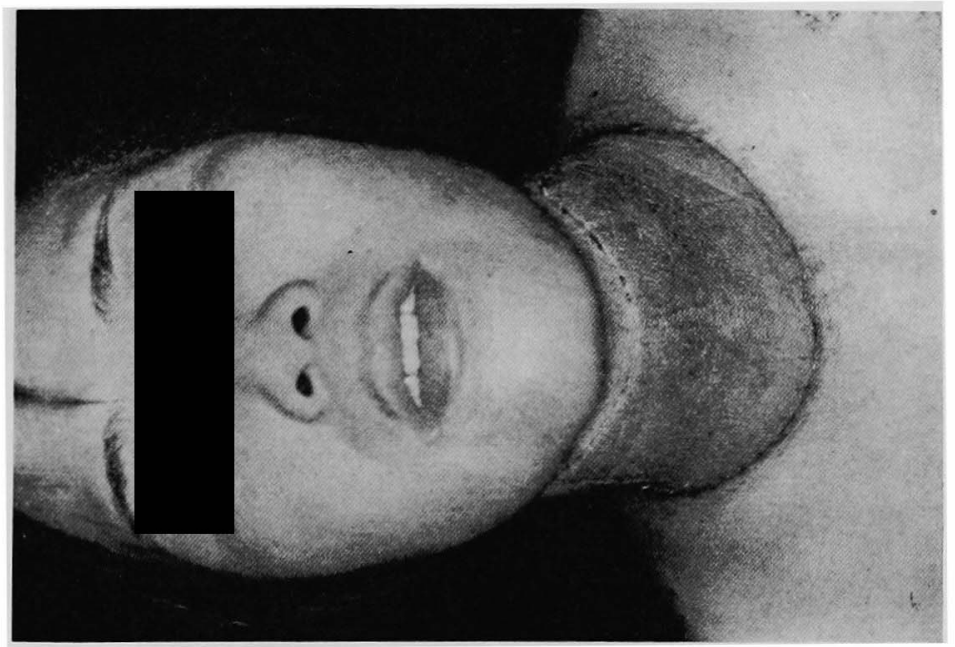

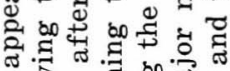

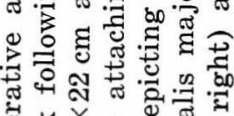

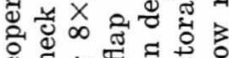

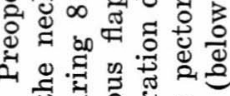
出. 。

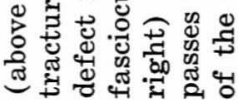
든 完 


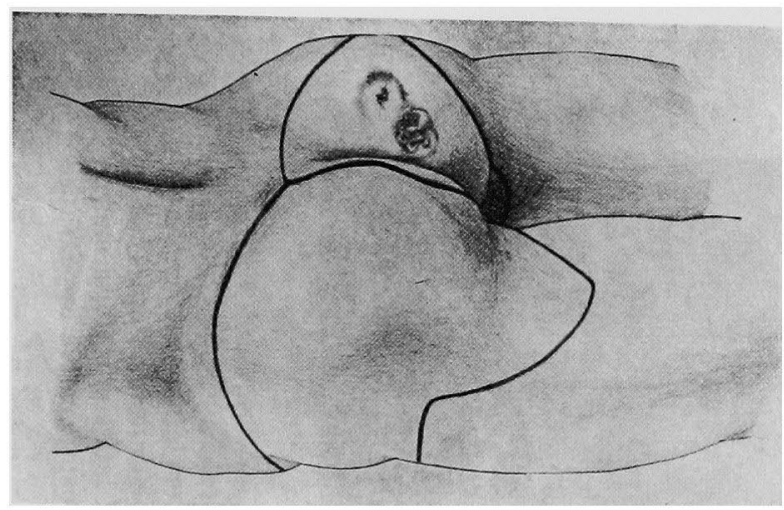

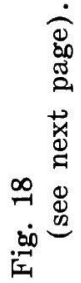
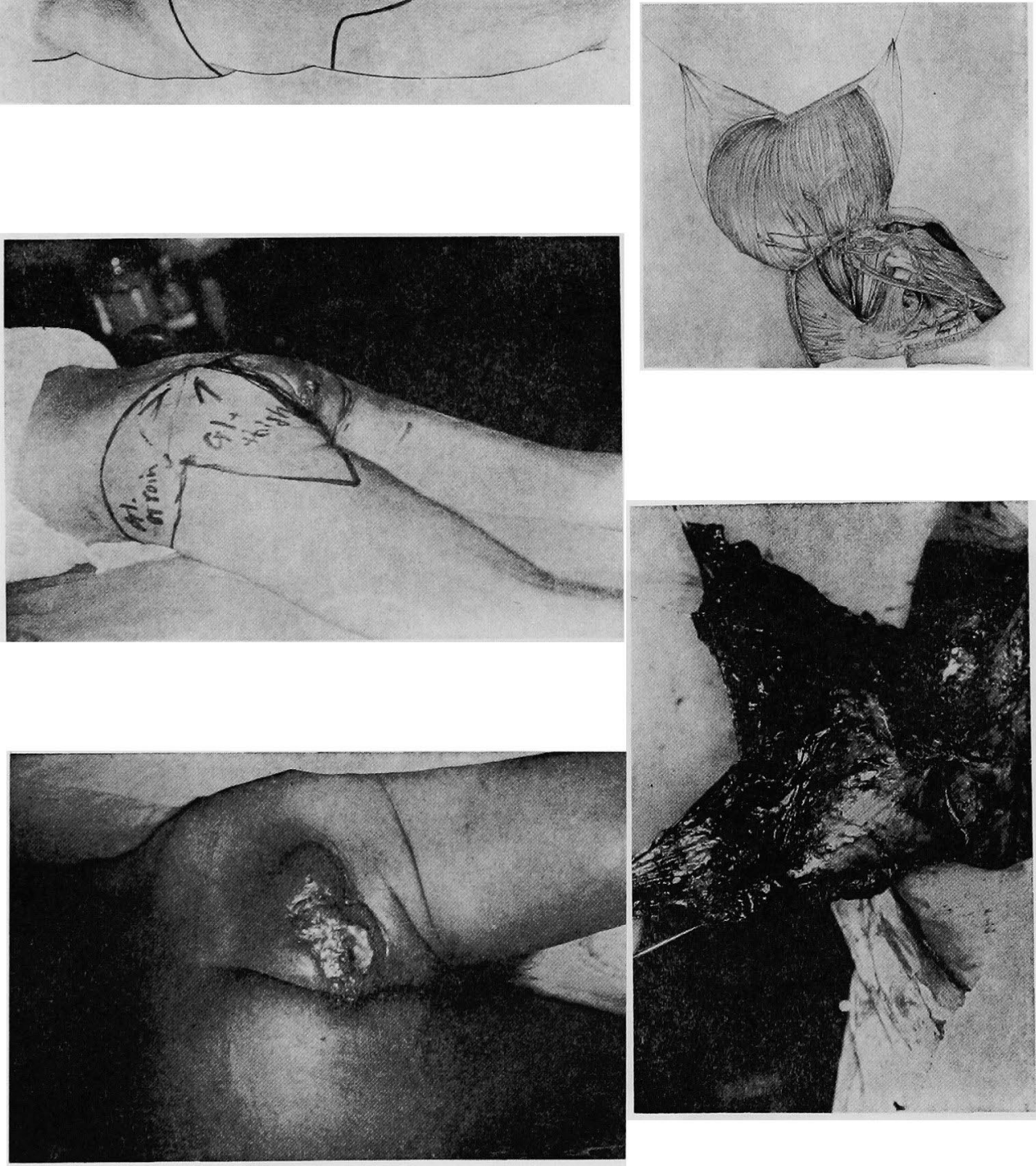

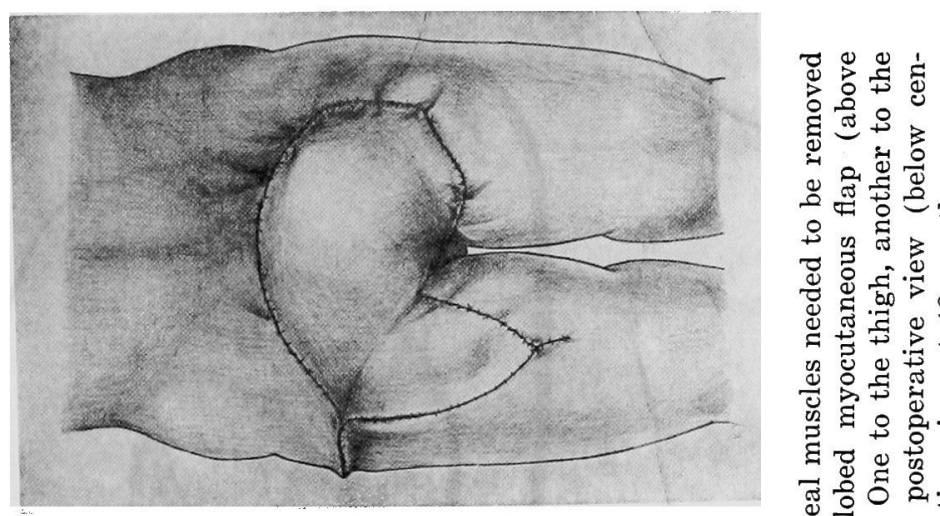

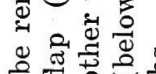

+ थ

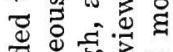

8 .

$\Rightarrow+\$$

叫

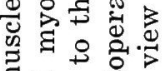

छ व

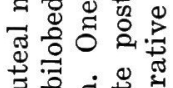

के

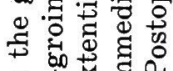

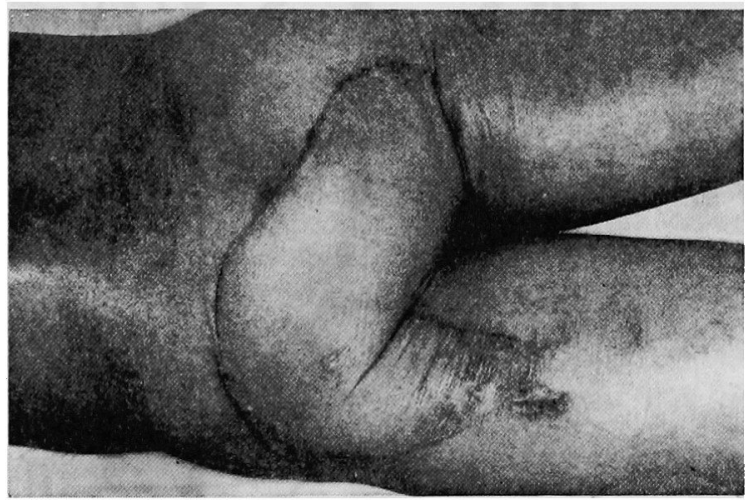

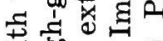

然产要

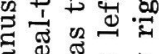

至

马

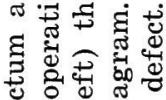

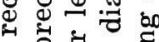

证.

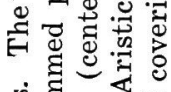

เू हี ส

ส

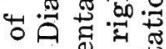

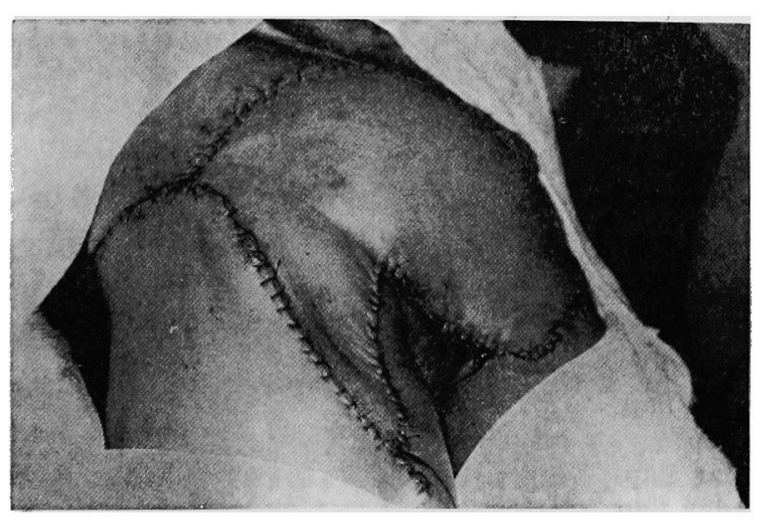

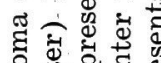

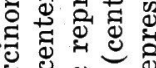

సٓ

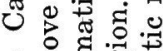

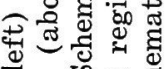

ڤั

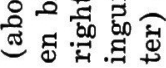

$\infty$

$\dot{0}$ 


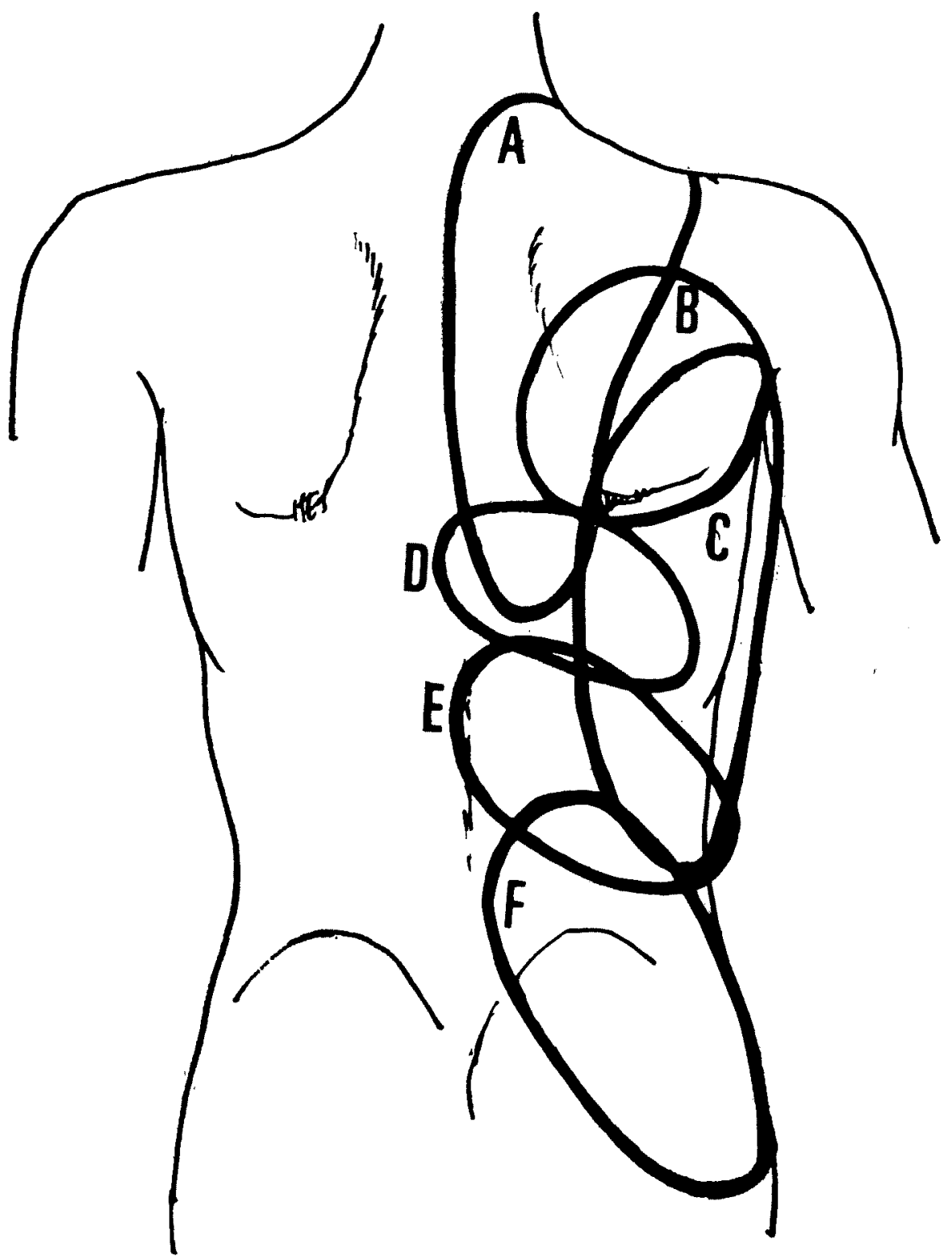

Fig. 19 The dorsal trunk is covered with several fasciocutaneous flaps in axial pattern.

A: Cervicodorsal flap

B: Scapular flap

C: Parascapular flap

D: Infrascapular flap

E: Subcostal flap (Vascular pedicle is the 12th intercostal vessel.)

F: Lumbogluteal flap 